\title{
Karbon Emisyonu ve Enerji Tüketiminin Büyüme Üzerindeki Etkileri: MIST Ülkeleri Karşılaştırmasıı
}

\author{
Mustafa GÜLL Ü, Department of Economics, Faculty of Economics and Administrative Sciences, Cankiri \\ Karatekin University, Turkey; e-mail: mustafagullu@hotmail.com
}

Harun YAKIŞIK, Department of Economics, Faculty of Economics and Administrative Sciences, Cankiri Karatekin University, Turkey; e-mail: haruny@karatekin.edu.tr

\section{The Impact of Carbon Emission and Energy Consumption on Economic Growth: A Comparison of the MIST Countries2}

\begin{abstract}
The aim of this study is to test whether there is any kind of causality between carbon emissionsenergy consumption and economic growth in the newly formation of countries; Mexico, Indonesia, South Korea and Turkey (MIST). With this target in mind, per capita carbon emission, per capita energy consumption, and per capita gross domestic product data has been analyzed in line with Johansen Cointegration and Granger Causality Test between the years of 1971-2010. According to the results, it has revealed that there is a one-way causality from economic growth to carbon emissions and energy consumption, in other words, carbon emission and energy consumption are not causes of economic growth.

Keywords

: $\quad$ Carbon Emission, Energy Consumption, Economic Growth, MIST

Countries, Causality Analysis.

JEL Classification Codes : F43, O13, O44, P18, Q43.

\section{$\ddot{O} z$}

Bu çalışmanın amacı, yeni bir uluslararası oluşum olan Meksika, Endonezya, Güney Kore ve Türkiye (MIST) ülkelerinde, karbon emisyonu ve enerji tüketimi ile ekonomik büyüme arasında nedensellik ilişsisini test etmektir. Bu amaçla, MIST ülkelerinin 1971-2010 dönemi için, kişi başına düşen karbondioksit emisyonu, enerji tüketimi ve Gayrisafi Yurt İçi Hâsıla yıllık verileri kullanılarak, Johansen Eşbütünleşme ve Granger Nedensellik Testi yapılmıştır. Çalışmanın sonuçlarına göre, MIST ülkelerinde ekonomik büyümeden karbon emisyonu ve enerji tüketimine doğru tek yönlü bir nedensellik olduğu yani karbon emisyonu ve enerji tüketiminin büyümenin nedeni olmadığ bulgusu elde edilmiştir.
\end{abstract}

Anahtar Sözcükler $\quad$ : Karbon Emisyonu, Ekonomik Büyüme, Enerji Tüketimi, MIST Ülkeleri, Nedensellik Analizi.

I Bu çalışma ilk yazarın Çankırı Karatekin Üniversitesi, Sosyal Bilimler Enstitüsü, İktisat Anabilim Dalında hazırlamış olduğu aynı isimli yüksek lisans tezinden üretilmiştir.

2 This paper is derived from the same titled master thesis of the first author in Cankiri Karatekin University, Department of Economics. 


\section{Giriş}

Tarihi süreç içerisinde toplumlar sürekli enerjiye ihtiyaç duymuşlardır. Sürdürülebilir kalkınmayı gerçekleştirebilmek için rezervleri sınırlı olan fosil yakıtlar yerine rüzgâr enerjisi, güneş enerjisi ve hidro-enerji gibi karbon salınımı olmayan alternatif enerji kaynaklarının kullanılması önem arz etmektedir (Altıntaş, 2013: 265).

Karbon emisyonu, karbon içeren fosil yakıtların yanması sonucu oluşan $\mathrm{CO}_{2}$ 'nin atmosfere karışması olarak ifade edilmektedir. Karbon Emisyonu kavramının çok büyük bir kısmını karbondioksit oluşturduğundan ve diğer sera gazları da karbon eş değeri olarak çevrildiğinden literatürde genellikle sera gazları emisyonu olarak da yer almaktadır (Çevre ve Orman Bakanlığı, 2011: 1). Karbon emisyonunu belirleyen faktörler; ekonomik büyüme, enerji tüketimi, ormansızlaştırma, nüfus artışı ve kişi başına düşen milli gelir olarak gruplandırılabilir (Karakaya \& Özçağ, 2003: 12). ABD gibi gelişmiş ülkelerde enerji kaynağının büyük bir oranı fosil yakıtlardan temin edilmekte, kömür ve petrol gibi yakıtların kullanımı sırasında enerjinin çevreye vereceği zarar çok fazla göz önünde bulundurulmamaktadır. Bu süreçte dikkatleri çeken konu, enerjinin bir şekilde elde edilmesi ve kullanılması gerektiğidir (Geller, 2002: 1). Özellikle gelişmekte olan ve azgelişmiş ülkeler açısından ekonomik büyüme temel bir hedeftir. Temel doğal kaynakların korunarak ekonomik büyümenin gerçekleştirilmesi sürdürülebilir büyüme açısından önemi yadsınamaz (Munasinghe, 2001: 43).

Son dönemlerde yükselen ekonomiler olarak görülen MIST ülkeleri, jeoekonomik ve nüfus büyüklüğü açısından bölgelerinde önemli güç olarak değerlendirilmektedirler. MIST ülkeleri, BRICS ülkeleri gibi bir oluşum içerisinde bir araya getirilerek küresel ekonomiye ivme kazandırılması amaçlanmıştır. Grubu oluşturan ülkelerin ortak yönleri ekonomileri, kalabalık nüfusları, yüzölçümleri, büyük pazarları ve büyüme hızlarıdır. Bu ülkelerin hepsinin ihracatlarının ekonomilerinde çok büyük bir orana sahip olmaları, grup ülkelerinin hepsinin G-20 üyesi olmaları ve Endonezya dışındaki ülkelerin OECD üyesi olmaları uluslararası teşkilatlarla entegre olduklarını göstermektedir. MIST ülkeleri grubunun kurumsal yapıya kavuşması, ekonomi politikalarını uyumlaştırmaları, grup içi ticareti geliştirmeleri, bölgesel ve küresel örgütlerler iyi ilişkiler kurması ve grubun iyi işbirliği örnekleri sergilemesiyle uzun dönemde küresel ekonomik büyümeye önemli bir katk1 sağlayacağı öngörülmektedir (Elbasan, 2011). Bu çalışmada MIST grubu ülkelerin inceleme konusu yapılması bu ülkelerin yüksek büyüme performanslarına enerji tüketimi ve karbon emisyonunun etkisini test etmektir. Böylece MIST ülkeleri özelinde yapılan analiz sonuçları ışığında diğer ülkelere yönelik bir alternatif enerji projeksiyonu sunarak politika yapıcılara katkı sağlanması hedeflenmektedir.

Bu bağlamda çalışmanın amacı; seçilen ülkelerin (MIST) büyümeleri üzerinde enerji tüketiminin ve karbon emisyonunun etkili olup olmadığını test etmek ve elde edilen sonuçlar doğrultusunda ülkelerin temiz enerji politikalarının oluşturulmasına katkı yapmaktır. 
Çalışma bu yönüyle MIST ülkeleriyle ilgili-literatürdeki boşluğu dolduracağı öngörülmektedir.

Çalışma üç bölümden oluşmaktadır. Birinci bölümde, karbon emisyonu, ekonomik büyüme ve enerji tüketimi konularıyla ilgili temel literatür çalışmalarına yer verilmiştir. İkinci bölümde enerji tüketimi, karbon emisyonu ve büyüme ilişkisi ele alınmıştır. Çalışmanın son bölümü olan üçüncü bölümde ise, 1971-2010 yılları arasında MIST grubu ülkelerinde, karbon emisyonu, enerji tüketiminin ekonomik büyümeye olan etkisi, Granger nedensellik analiziyle test edilmiştir.

\section{Literatür}

Son dönemlerde çevre bilincinin artırılması ve sürdürülebilir ekonomik büyümeyi gerçekleştirebilmek için hem gelişmiş hem de gelişmekte olan ülkelerde büyüme, enerji tüketimi ve karbon emisyonu konularında yapılan çalışmaların ve çevre düzenlemelerin arttığını görmekteyiz. Aksi takdirde çevresel etkileri içermeyen büyüme politikalarının ulusal ve uluslararası boyutlarda insan ve çevre sağlığını tehdit eder hale geleceği bilinen bir gerçektir.

Karbon emisyonu, enerji tüketimi ve ekonomik büyüme konularında yapılan çalışmaların özeti Tablo 1'de verilmiştir. Bu çalışmaları üç farklı kategoride sınıflandırmak mümkündür.

$\mathrm{Bu}$ çalışmalardan birinci grup çalışmaların enerji tüketimi ile karbon emisyonu arasındaki ilişkiyi incelediklerini görmekteyiz (Heidari vd., 2015; Soytaş vd., 2007).

İkinci grup çalışmalara baktığımızda karbon emisyonu ile ekonomik büyüme arasındaki ilişkiyi araştıran çalışmalardır (Bloch vd., 2012; Abid, 2015; Loganathan vd., 2014; Van vd., 2013; Kofi vd., 2012; Lotfalipour, 2010; Tutulmaz vd., 2012; Ari vd., 2011; Liao vd., 2013; Sarısoy vd., 2013; Cowan vd., 2014; Alkhathlan vd., 2013).

Üçüncü grup çalışmaların ise ekonomik büyüme, karbon emisyonu ve enerji tüketimi arasındaki ilişki üzerinde yoğunlaştığı görülmektedir (Hossain, 2011; Zhang vd., 2009; Öztürk vd., 2013; Acaravcı vd., 2010; Menyah vd., 2010; Alam vd., 2011; Fei vd., 2011; Alshehry vd., 2015; Halicioglu, 2009; Omri, 2013; Kasman vd., 2015; Sbia vd., 2014; AlMulali vd., 2012; Shahbaz vd., 2013; Özcan, 2013; Jahangir vd., 2012; Bastola vd., 2014; Pao vd., 2011; Arouri vd., 2012; Altıntaş, 2013; Aytun, 2014; Saboori vd., 2014; Park vd., 2013).

Ancak MIST ülkeleri için karbon emisyonu, enerji tüketimi ve ekonomik büyüme parametrelerini kullanarak yapılan çalışma yok denecek kadar azdır. Bu çalışmalardan Pao ve diğ. (2014) yılında yaptığı çalışma önem arz etmektedir. Pao ve diğ. yaptıkları çalışmada Endonezya, Güney Kore ve Türkiye için temiz ve temiz olmayan enerji ile ekonomik büyüme arasındaki ilişkiyi incelemiştir. 


\section{Tablo: 1}

Karbon Emisyonu, Enerji Tüketimi ve Ekonomik Büyüme: Literatür Özeti

\begin{tabular}{|c|c|c|c|}
\hline Yazar & İncelenen Dönem & Ülke & Nedensellik Yönü \\
\hline Zhang vd. (2009) & 1960-2007 & Çin & $\mathrm{E} \rightarrow \mathrm{K}$ \\
\hline Hossain (2011) & 1971-2007 & $\begin{array}{l}\text { Brezilya, Cin, Malezya, Meksika, Hindistan, } \\
\text { Güney Afrika, Filipinler, Türkiye ve Tayland }\end{array}$ & $\begin{array}{l}\mathrm{B} \rightarrow \mathrm{E} \\
\mathrm{B} \rightarrow \mathrm{K}\end{array}$ \\
\hline Heidari vd. (2014), & $1980-2008$ & Endonezya, Malezya, Filipinler, Singapur ve Tayland & $\mathrm{E} \rightarrow \mathrm{K}$ \\
\hline Abid (2015) & $1980-2009$ & Tunus & $\mathrm{E} \leftrightarrow \mathrm{K}$ \\
\hline Alam vd. (2011) & 1971-2006 & Hindistan & $\mathrm{E} \leftrightarrow \mathrm{K}$ \\
\hline Cowan vd. (2014) & $1990-2010$ & BRICS ülkeleri & Çeşitli \\
\hline Fei vd. (2011) & 1985-2007 & Çin & $\mathrm{B} \leftrightarrow \mathrm{E}$ \\
\hline Alshehry vd. (2015) & $1971-2010$ & Suudi Arabistan & $\mathrm{E} \leftrightarrow \mathrm{K}$ \\
\hline Omri (2013) & 1990-2011 & MENA ülkeleri & $\begin{array}{l}\mathrm{B} \leftrightarrow \mathrm{E} \\
\mathrm{B} \leftrightarrow \mathrm{K}\end{array}$ \\
\hline Kasman vd. (2015) & $1992-2010$ & 15 ülke & $\mathrm{E} \rightarrow \mathrm{K}$ \\
\hline Loganathan vd. (2014) & $1974-2010$ & Malezya & $\mathrm{B} \rightarrow \mathrm{K}$ \\
\hline Soytaş vd. (2007) & 1960-2004 & Amerika Birleşik Devletleri & $\mathrm{K} \rightarrow \mathrm{E}$ \\
\hline Shahbaz vd. (2013) & 1975-2011 & Endonezya & $\mathrm{B} \leftrightarrow \mathrm{K}$ \\
\hline Özcan (2013) & 1990-2008 & 12 Orta Doğu ülkesi & $\begin{array}{l}\mathrm{E} \leftrightarrow \mathrm{K} \\
\mathrm{B} \leftrightarrow \mathrm{K}\end{array}$ \\
\hline Jahangir vd. (2012) & $1972-2006$ & Bangladeş & $\mathrm{B} \leftrightarrow \mathrm{K}$ \\
\hline Salahuddin vd. (2014) & $1980-2012$ & Körfez İșbirliği Ülkeleri & $\mathrm{B}$ ile $\mathrm{K}$ arasında ilişki yok \\
\hline Lotfalipour (2010) & 1967-2007 & İran & $\begin{array}{l}\mathrm{B} \rightarrow \mathrm{K} \\
\mathrm{E} \rightarrow \mathrm{K}\end{array}$ \\
\hline Bastolavediğ.(2014) & $1980-2011$ & Nepal & $\begin{array}{l}\mathrm{E} \leftrightarrow \mathrm{K} \\
\mathrm{B} \rightarrow \mathrm{K} \\
\mathrm{B} \rightarrow \mathrm{E}\end{array}$ \\
\hline Arouri vd. (2012) & $1981-2005$ & 12 Ortadoğu ülkesi ve Kuzey Afrika ülkeleri (MENA) & $\mathrm{E} \rightarrow \mathrm{K}$ \\
\hline Saboori vd. (2014) & $1960-2008$ & OECD ülkeleri & $\mathrm{B} \rightarrow \mathrm{K}$ \\
\hline Altıntaş (2013) & $1970-2008$ & Türkiye & $\begin{array}{l}\mathrm{B} \rightarrow \mathrm{K} \\
\mathrm{E} \rightarrow \mathrm{K}\end{array}$ \\
\hline
\end{tabular}

Not: $\rightarrow$ Tek yönlü Granger Nedenselliği, $\leftrightarrow$ ise çift yönlü Granger Nedenselliği göstermektedir. K, Karbon emisyonunu, E, Enerji Tüketimini ve B ise Ekonomik Büyümeyi ifade etmektedir.

Yapılan çalışmalardaki ekonometrik analiz sonuçlarının yoğunlaştığı konu, enerji tüketiminden karbon emisyonuna doğru ve büyümeden karbon emisyonuna doğru Granger Nedensellik olmuştur. Buna karşılık karbon emisyonunun enerji tüketiminin Granger nedenselliği olduğu sonucu en az elde edilen sonuçlardan olmuştur.

\section{Ampirik Model}

Kişi başına düşen enerji tüketimi (EU) ile reel gayrisafi yurt içi hasılanın (GDP), kişi başına düşen karbondioksit emisyonu $\left(\mathrm{CO}_{2}\right)$ üzerindeki etkisini tespit etmek için kullanılacak olan ampirik model Denklem 1'de gösterildiği gibidir:

$$
L C O 2_{t}=\beta_{0}+\beta_{1} L E U_{t}+\beta_{2} L G D P_{t}+\varepsilon_{t}
$$

Denklem 1'de kişi başına düşen karbondioksit emisyonu $\mathrm{CO}_{2}$ ile kişi başına düşen enerji tüketimi EU ile ve reel gayrisafi yurt içi hâsıla GDP (2005 fiyatlarıla, ABD \$) ile gösterilmiş olup, ayrıca serilerin varyansındaki değişmeyi yumuşatmak ve otokorelasyon olasılı̆̆ına karşı koruyabilmek amacıyla serilerin logaritmik dönüşümleri alınmıştır (Dursun, 2015: 103). Kişibaşına düşen enerji tüketimindeki "kg petrol eşdeğeri" hesaplanırken birincil enerji ve birincil elektrik gibi tüm enerji türleri petrol eşdeğerine dönüştürülmüştür. Ayrıca nükleer elektriği petrol eşdeğerlerine dönüştürmek için yüzde 33'lük bir 1sı verimliliği varsayılmış, hidroelektrik enerjiyi dönüştürmek için yüzde yüzlük bir 1sı verimliliği varsayılmaktadır (Dünya Bankası Veritabanı, 2014). Analizde kullanılan 
değişkenler ve kısaltmaları Tablo 2'de gösterilmiştir. Ayrıca analizde kullanılan değişkenlerin grafikleri EK-1 bölümünde gösterilmiştir.

Tablo: 2

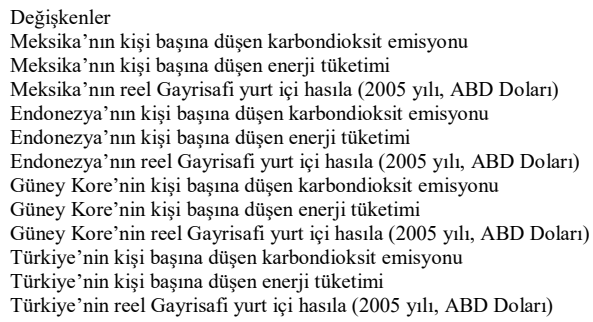

\section{Ekonometrik Analizde Kullanılan Değişkenler}

$\begin{array}{ll}\text { Kısaltması } & \text { Birim } \\ \text { LMCO2 } & \text { Metrik Ton } \\ \text { LMEU } & \text { Kg Petrol Eşdeğeri } \\ \text { LMGDP } & \text { Amerikan Doları } \\ \text { LECO2 } & \text { Metrik Ton } \\ \text { LEEU } & \text { Kg Petrol Eşdeğeri } \\ \text { LEGDP } & \text { Amerikan Doları (2005 ABD \$) } \\ \text { LGCO2 } & \text { Metrik Ton } \\ \text { LGEU } & \text { Kg Petrol Eşdeğeri } \\ \text { LGGDP } & \text { Amerikan Doları (2005 ABD \$) } \\ \text { LTCO2 } & \text { Metrik Ton } \\ \text { LTEU } & \text { Kg Petrol Eşdeğeri } \\ \text { LTGDP } & \text { Amerikan Doları (2005 ABD \$) }\end{array}$

\section{Yöntem}

Çalışmada öncelikle yapısal kırılmaların dikkate alınmadı̆̆ı Genişletilmiş DickeyFuller (ADF) testi, ardından Phillips Perron (PP) testi, daha sonra yapısal kırılmalı ZivotAndrews birim kök testi kullanılmıştır. Birim kökler araştırıldıktan sonra seriler arasında uzun dönemde karşılıklı bir ilişkinin bulunup bulunmadığını araştırmak amacıyla JohansenJuselius (1990) tarafından geliştirilmiş Johansen eşbütünleşme testi yapılmıştır. Değişkenler arasındaki ilişkinin yönünün belirlenmesinde Granger nedensellik testi kullanılmıştır.

Tablo: 3

ADF Birim Kök Testi Sonuçları

\begin{tabular}{|c|c|c|c|c|c|c|}
\hline \multirow{2}{*}{ Değişkenler } & \multicolumn{3}{|c|}{ Düzey } & \multicolumn{3}{|c|}{ Birinci Farklar } \\
\hline & Sabitsiz & Sabitli & Sabitli/ Trendli & Sabitsiz & Sabitli & Sabitli/ Trendli \\
\hline LMCO2 & $1.165(1)$ & $-3.045(0)$ & $-2.263(0)$ & $-6.616(0)$ & $-6.908(0)$ & $-7.659(0)$ \\
\hline LMEU & $2.724(0)$ & $-4.392(0)$ & $-2.816(0)$ & $-4.005(0)$ & $-4.357(0)$ & $-4.871(0)$ \\
\hline LMGDP & $5.634(0)$ & $-2.806(0)$ & $-2.689(0)$ & $-3.171(0)$ & $-4.585(0)$ & $-4.819(0)$ \\
\hline LECO2 & $-2.222(0)$ & $-1.612(0)$ & $-2.906(0)$ & $-4.781(0)$ & $-5.740(0)$ & $-5.784(0)$ \\
\hline LEEU & $4.683(0)$ & $-0.606(0)$ & $-1.694(0)$ & $-4.151(0)$ & $-6.146(0)$ & $-6.093(0)$ \\
\hline LEGDP & $9.197(0)$ & $-2.191(0)$ & $-1.543(0)$ & $-2.141(0)$ & $-4.323(0)$ & $-4.551(0)$ \\
\hline LGCO2 & $3.747(0)$ & $-2.182(0)$ & $-1.467(0)$ & $-3.961(0)$ & $-6.226(0)$ & $-7.063(0)$ \\
\hline LGEU & $6.775(0)$ & $-2.500(0)$ & $-0.509(0)$ & $-1.002(0)$ & $-5.382(0)$ & $-6.185(0)$ \\
\hline LGGDP & $10.94(0)$ & $-3.352(0)$ & $-0.270(0)$ & $-1.237(4)$ & $-4.732(0)$ & $-6.131(0)$ \\
\hline LTCO2 & $2.734(0)$ & $-1.315(0)$ & $-3.024(0)$ & $-4.980(0)$ & $-6.107(0)$ & $-6.026(0)$ \\
\hline LTEU & $3.475(0)$ & $-1.214(0)$ & $-3.559(0)$ & $-5.046(0)$ & $-6.229(0)$ & $-6.106(0)$ \\
\hline LTGDP & $6.035(0)$ & $-0.724(0)$ & $-3.119(0)$ & $-2.116(1)$ & $-6.300(0)$ & $-6.204(0)$ \\
\hline \%1 Kritik Değeri & -2.625 & -3.610 & -4.211 & -2.627 & -3.615 & -4.219 \\
\hline$\% 5$ Kritik Değeri & -1.949 & -2.938 & -3.529 & -1.949 & -2.941 & -3.533 \\
\hline \%10 Kritik Değeri & -1.611 & -2.607 & -3.196 & -1.611 & -2.609 & -3.198 \\
\hline
\end{tabular}

Not: ADF testi için parantez içindeki gecikme uzunlukları Schwarz Bilgi Kriterine göre belirlenmiş olup, kritik değerler MacKinnon'dan (1996) alınmıştır. Maksimum gecikme uzunluğu 9 olarak alınmıştır.

\section{Araştırma Bulguları}

Modelin tahminine geçmeden önce modelde kullanılacak değişkenlerin zaman serisi özelliklerinin anlamlılık düzeylerinin ortaya konulması gerekmektedir. Değişkenlerin Augmented Dickey Fuller (ADF) ve Phillips-Perron (PP) birim kök test sonuçları Tablo 3 ve Tablo' 4 te raporlanmıştır. Bunun yanında serilerin yapısal kırılmalı Zivot-Andrews birim kök test sonuçları Tablo 5'te raporlanmıştır. Araştırma bulgularından Eşbütünleşme gecikme uzunluğu test sonuçları Tablo 6'da, Johansen Eşbütünleşme test sonuçları Tablo 
7'de ve Granger Nedensellik test sonuçları Tablo 8'de raporlanmıştır. Ayrıca analizde kullanılan verilerin ülke bazında grafiksel gösterimi EK-2 bölümünde detaylı olarak verilmiştir.

Tablo: 4

PP Birim Kök Testi Sonuçları

\begin{tabular}{lllllll}
\hline \multirow{2}{*}{ Değişkenler } & \multicolumn{3}{c}{ Düzey } & \multicolumn{2}{c}{ Birinci Farklar } \\
\cline { 2 - 7 } & Sabitsiz & \multicolumn{1}{c}{ Sabitli } & Sabitli/ Trendli & Sabitsiz & Sabitli & Sabitli/ Trendli \\
\hline LMCO2 & $0.995(3)$ & $-3.218(1)$ & $-2.223(1)$ & $-6.627(3)$ & $-6.868(3)$ & $-7.539(2)$ \\
LMEU & $1.901(4)$ & $-4.031(2)$ & $-2.710(2)$ & $-4.018(4)$ & $-4.398(3)$ & $-4.943(3)$ \\
LMGDP & $4.763(2)$ & $-2.638(1)$ & $-2.698(1)$ & $-3.071(1)$ & $-4.579(1)$ & $-4.780(2)$ \\
LECO2 & $-2.104(2)$ & $-2.17(1)$ & $-2.696(6)$ & $-4.781(0)$ & $-5.954(9)$ & $-7.15(12)$ \\
LEEU & $4.821(2)$ & $-0.605(3)$ & $-1.748(1)$ & $-4.213(3)$ & $-6.148(2)$ & $-6.099(3)$ \\
LEGDP & $7.210(3)$ & $-2.002(2)$ & $-1.657(2)$ & $-2.141(0)$ & $-4.327(1)$ & $-4.570(1)$ \\
LGCO2 & $2.904(4)$ & $-2.646(4)$ & $-1.387(0)$ & $-4.198(4)$ & $-6.226(2)$ & $-7.243(2)$ \\
LGEU & $5.101(4)$ & $-2.541(2)$ & $-0.485(2)$ & $-2.682(3)$ & $-5.439(3)$ & $-6.185(1)$ \\
LGGDP & $8.605(3)$ & $-3.780(4)$ & $-0.019(4)$ & $-0.019(0)$ & $-0.019(2)$ & $-6.211(6)$ \\
LTCO2 & $2.650(1)$ & $-1.338(3)$ & $-3.024(0)$ & $-4.962(2)$ & $-6.251(5)$ & $-6.134(5)$ \\
LTEU & $3.482(1)$ & $-1.214(0)$ & $-3.648(1)$ & $-5.050(3)$ & $-6.269(2)$ & $-6.130(2)$ \\
LTGDP & $6.207(2)$ & $-0.730(2)$ & $-3.218(1)$ & $-3.784(4)$ & $-6.303(3)$ & $-6.204(3)$ \\
\hline \%1 Kritik Değeri & -2.625 & -3.610 & -4.211 & -2.627 & -3.615 & -4.219 \\
\%5 Kritik Değeri & -1.949 & -2.938 & -3.529 & -1.949 & -2.941 & -3.533 \\
\%10 Kritik Değeri & -1.611 & -2.607 & -3.196 & -1.611 & -2.609 & -3.198 \\
\hline
\end{tabular}

Not: PP testi için parantez içindeki gecikme uzunlukları Newey-West Kriterine göre otokorelasyonun bulunmadiğg minimum gecikmeler olarak belirlenmiştir.

Tablo: 5

Zivot Andrews Birim Kök Testi Sonuçları

\begin{tabular}{|c|c|c|c|c|c|c|}
\hline \multirow[b]{2}{*}{ Düzey Değerleri } & \multicolumn{2}{|c|}{$\begin{array}{c}\text { Model A } \\
\text { (Düzeyde Kırılma) }\end{array}$} & \multicolumn{2}{|c|}{$\begin{array}{c}\text { Model B } \\
\text { (Eğimde Kırılma) }\end{array}$} & \multicolumn{2}{|c|}{$\begin{array}{c}\text { Model C } \\
\text { (Düzey ve Eğimde Kırılma) }\end{array}$} \\
\hline & Test İstatistiği & Kırılma Tarihi & Test İstatistiği & Kırılma Tarihi & Test İstatistiği & Kırılma Tarihi \\
\hline LMCO2 & $-3.881(0)$ & 1978 & $-4.804(0)$ & 1981 & $-5.108(0)$ & 1983 \\
\hline LMEU & $-4.480(0)$ & 1978 & $-4.499(0)$ & 1981 & $-4.480(0)$ & 1978 \\
\hline LMGDP & $-2.902(3)$ & 2001 & $-4.126(1)$ & 1980 & $-4.277(6)$ & 2005 \\
\hline $\mathrm{LECO2}$ & $-3.993(1)$ & 1998 & $-3.115(0)$ & 1991 & $-3.762(1)$ & 1998 \\
\hline LEEU & $-5.474(0)$ & 1990 & $--2.789(0)$ & 1997 & $-6.091(0)$ & 1990 \\
\hline LEGDP & $-8.859(1)$ & 1998 & $-3.329(1)$ & 1998 & $-7.847(1)$ & 1998 \\
\hline LGCO2 & $-2.889(0)$ & 1998 & $-3.963(0)$ & 1996 & $-4.102(0)$ & 1993 \\
\hline LGEU & $-1.983(0)$ & 1986 & $-3.301(0)$ & 1997 & $-3.582(0)$ & 1990 \\
\hline LGGDP & $-1.830(0)$ & 1983 & $-3.379(0)$ & 1995 & $-3.275(0)$ & 1994 \\
\hline LTCO2 & $-4.133(0)$ & 1985 & $-3.115(0)$ & 1991 & $-4.167(0)$ & 1985 \\
\hline LTEU & $-4.665(4)$ & 1990 & $-4.225(4)$ & 1982 & $-5.121(4)$ & 1987 \\
\hline LTGDP & $-5.291(3)$ & 1990 & $-4.465(3)$ & 1997 & $-5.410(3)$ & 1987 \\
\hline Birinci Fark Değerleri & Test İstatistiği & Kırılma Tarihi & Test İstatistiği & KIrılma Tarihi & Test İstatistiği & Kırılma Tarihi \\
\hline LMCO2 & $-9.898(0)$ & 1983 & $-8.334(0)$ & 19885 & $-9.761(0)$ & 1983 \\
\hline LMEU & $-6.846(0)$ & 1983 & $-5.509(0)$ & 1987 & $-6.922(0)$ & 1982 \\
\hline LMGDP & $-6.146(0)$ & 1982 & $-5.165(0)$ & 1984 & $-6.171(0)$ & 1982 \\
\hline $\mathrm{LECO} 2$ & $-6.285(0)$ & 1979 & $-5.852(0)$ & 1982 & $-6.507(0)$ & 1979 \\
\hline LEEU & $-6.679(0)$ & 1986 & $-6.422(0)$ & 1991 & $-6.751(0)$ & 1990 \\
\hline LEGDP & $-5.286(0)$ & 1997 & $-4.801(0)$ & 2000 & $-7.067(0)$ & 1998 \\
\hline LGCO2 & $-7.513(0)$ & 1998 & $-7.054(0)$ & 1982 & $-7.675(0)$ & 1998 \\
\hline LGEU & $-7.169(0)$ & 1986 & $-6.423(0)$ & 1991 & $-7.072(0)$ & 1986 \\
\hline LGGDP & $-6.766(0)$ & 1983 & $-6.150(0)$ & 1988 & $-7.125(0)$ & 1982 \\
\hline LTCO2 & $-6.368(0)$ & 1978 & $-6.118(0)$ & 1979 & $-6.678(0)$ & 1981 \\
\hline LTEU & $-6.567(0)$ & 1978 & $-6.331(0)$ & 1979 & $-6.708(0)$ & 1982 \\
\hline LTGDP & $-4.807(4)$ & 1998 & $-4.282(4)$ & 1989 & $-4.879(4)$ & 1998 \\
\hline
\end{tabular}

Not: Tablo kritik değerleri Model A için \%1; -5.34, \%5; -4.80, Model B için \%1; -4.93, \%5; -4.42, Model C için $\% 1$; - 5.57, \%5; -5.08'dir.Test istatistiğine ilişkin kritik değerler Zivot-Andrews (1992)'den alınmıştır. Optimal gecikme uzunlukları Schwarz bilgi kriterine göre belirlenmiştir. Tüm veriler için maximum gecikme uzunluğu 4 olarak alınmıştır.

ADF ve PP birim kök test sonuçlarına göre tüm serilerin entegre seviyede I(1) durağandır. Değişkenlerin tümü istatistiki açıdan \%1 ve \%5 önem düzeylerinde durağan 
çıkmışlardır. Buna göre çalışmada ele alınan verilerin hepsinin birinci farklarında I(1) durağan hale geldikleri veya birim kök içermedikleri gözlenmektedir.

Yapısal kırılmaları dikkate alan Zivot Andrews birim kök testi sonuçları ise Tablo 5 'te sunulmuştur. Tabloda MIST ülkeleri için Zivot Andrews testi sonuçları için Model A, Model B ve Model C'ye ait sonuçlara yer verilmiştir. Model A sadece düzeyde kırılmayı, Model B eğimde kırılmayı dikkate alırken, Model $\mathrm{C}$ ise hem düzeyde hem de eğimde kırılmayı göz önüne almaktadır. Tabloda kırılma tarihleri de belirtilmiştir. Ayrıca uygun gecikme uzunluğu test istatistiğinin yanındaki parantez içindeki değerler ile gösterilmiştir.

Meksika'nın enerji tüketimi ve karbon emisyonu değişkenleri üzerinde 1982 yılında Meksika hükümetinin ABD'ye gönderdiği heyet ile dış borçlarını ödeyemeyeceğini bildirmesiyle başlayan Latin Amerika Borç krizinin, gayri safi yurt içi hâsıla verisi üzerinde ise 2001 yılında Doğu Asya krizinin etkileriyle dünya ticaretinde yavaşlamanın Meksika üzerinde de etkisi olduğu anlaşılmaktadır. LMGDP değişkeni serisinde 2001'de, LMEU ve LMCO2 verilerinde ise 1978 yılında düzeyde kırılma olduğu tespit edilmiştir. LMCO2, LMEU ve LMGDP serileri seviye değerinde, \%1 ve \%5 anlamlılık düzeyinde Model A, Model B ve Model C için, test istatistiği mutlak değerce kritik değerlerden küçük olduğundan birim kök içermektedir. LMCO2, LMEU ve LMGDP serisinin birinci fark1 alındığında ise Model A, Model B ve Model C için durağan hale geldiği gözlemlenmektedir. Dolayısıyla birinci farklarında durağandır.

Endonezya'nın karbon emisyonu ve Gayri safi yurtiçi hâsıla değişkenleri üzerinde, 1997 yılının temmuz ayında Tayland'da başlayan ve Endonezya ile birlikte birçok Doğu Asya ülkesini etkileyen Doğu Asya Mali krizinin, enerji tüketimi üzerinde ise Asya ülkeleri için büyük önem taşıyan Japonya'daki, 1990 Japonya krizin ve etkisi olduğu anlaşılmaktadır. LEEU değişkeni serisinde 1990'de, LECO2 ve LEGDP verilerinde ise 1998 yılında düzeyde kırılma olduğu tespit edilmiştir. LECO2, LEEU ve LEGDP serileri seviye değerinde, $\% 1$ ve $\% 5$ anlamlılık düzeyinde Model A, Model B ve Model C için, test istatistiği mutlak değerce kritik değerlerden küçük olduğundan birim kök içermektedir. LECO2, LEEU ve LEGDP serisinin birinci farkı alındığında ise Model A, Model B ve Model $\mathrm{C}$ için durağan hale geldiği gözlemlenmektedir. Dolayısıyla birinci farklarında durağandir.

Güney Kore’nin karbon emisyonu değişkeni üzerinde 1997 Doğu Asya mali krizinin, enerji tüketimi ve gayri safi yurtiçi hasıla değişkeni üzerinde ise 1982-1986 yılları arasında beşinci beş yıllık planla birlikte cari işlemler fazlası veren ekonominin ve Japon yeninin değerlenmesiyle bazı mallarda pazar payının Japonya'dan Güney Kore'ye geçmesinin olumlu etkileri olduğu anlaşılmaktadır. LGCO2 değişkeni serisinde 1998'de, LGEU değişkeni serisinde 1986'da ve LGGDP verilerinde ise 1983 yılında düzeyde kırılma olduğu tespit edilmiştir. LGCO2, LGEU ve LGGDP serileri seviye değerinde birim kök içermektedir. Serilerin birinci farkı alındığında ise Model A, Model B ve Model C için durağan hale geldiği gözlemlenmektedir. Dolayısıyla birinci farklarında durağandır. 
Türkiye'nin enerji tüketimi ve gayri safi yurtiçi hasıla değişkenleri üzerinde 1990 Körfez krizinin, karbon emisyonu üzerinde ise darbe sonrası uygulamaya konan 24 Ocak kararları sonrası yaşanan krizin etkisi olduğu anlaşılmaktadır. LTCO2 değişkeni serisinde 1985'de, LTEU ve LTGDP verilerinde ise 1990 yılında düzeyde kırılma olduğu tespit edilmiştir. LTCO2, LTEU ve LTGDP serileri seviye değerinde birim kök içermektedir. Serilerin birinci farkı alındığında ise Model A, Model B ve Model C için durağan hale geldiği gözlemlenmektedir. Dolayısıyla birinci farklarında durağandır. Eşbütünleşme testini uygulamadan önce hipotezleri tespit edip, VAR modeli oluşturarak uygun gecikme sayısı belirlenmiştir.

\begin{tabular}{lclllll}
\multicolumn{7}{c}{ Tablo: 6 } \\
& \multicolumn{7}{c}{ Gecikme Uzunluğu Sonuçları } \\
\hline \multirow{3}{*}{ Meksika } & Gecikme & LR & FPE & AIC & SC & HQ \\
& $\mathbf{0}$ & NA & $7.07 \mathrm{e}+08$ & 2.888 .983 & 2.902 .451 & 2.893 .576 \\
Endonezya & $\mathbf{1}$ & $124.267^{*}$ & $19131375^{*}$ & $25.27719^{*}$ & $25.81590^{*}$ & $25.46090^{*}$ \\
& $\mathbf{0}$ & NA & 19987751 & 2.532 .421 & 2.545 .889 & 2.537 .014 \\
Güney Kore & $\mathbf{1}$ & $179.5186^{*}$ & $85761.19^{*}$ & $19.86967^{*}$ & $20.40838^{*}$ & $20.05339^{*}$ \\
& $\mathbf{0}$ & NA & $5.77 \mathrm{e}+11$ & 3.559 .394 & 3.572 .862 & 3.563 .987 \\
Türkiye & $\mathbf{1}$ & $207.1065^{*}$ & $9.86 \mathrm{e}+08^{*}$ & $29.21980^{*}$ & $29.75852^{*}$ & $29.40352^{*}$ \\
& $\mathbf{0}$ & NA & $2.38+08$ & 2.780 .162 & 2.793 .629 & 2.784 .754 \\
\hline
\end{tabular}

Not: Kriterlere göre en uygun seçim * ile gösterilmiştir. LR: Ardışık Değiştirilmiş, LR test istatistiği, FPE: Final Tahmin Hatast, AIC: Akaike bilgi kriteri, SC: Schwarz bilgi kriteri, HQ: Hannan-Quinn bilgi kriteri.

Model için gecikme sayısı 6 gecikmeye kadar alınıp en uygun gecikme uzunluğu 1 olarak belirlendiğinden yukarıdaki tablo kısaltılarak ilk iki gecikme sayıları gösterilmiştir. Dolayısıyla eşbütünleşme analizi yapılırken 1 gecikme uzunluğu üzerinden işlem yapılacaktır. Johansen Eşbütünleşme testi değişkenlerin birinci farklarına uygulandıktan sonra sonuçlar Tablo 7'deki gibidir:

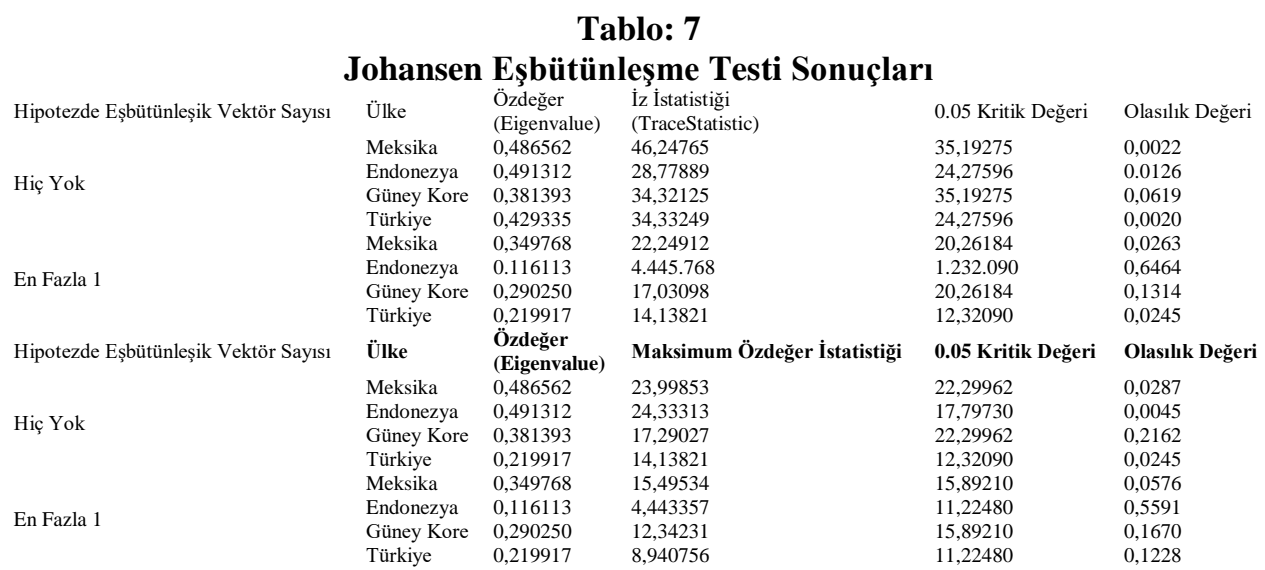

Ekonomik büyüme ve enerji tüketimin karbon emisyonu üzerindeki etkisinin analiz edileceği modelde bağıml değiş̧ken karbon emisyonu ( $\left.\mathrm{CO}_{2}\right)$ olup her ülke için ayrı ayrı tahmin edilecek uzun dönem denklemleri (2), (3), (4) ve (5)'de verilmiştir.

$$
L M C O 2_{t}=\beta_{0}+\beta_{1} L M E U_{t}+\beta_{2} L M G D P_{t}+\operatorname{res} 1_{t}
$$




$$
\begin{aligned}
& \operatorname{LECO}_{t}=\beta_{0}+\beta_{1} L E E U_{t}+\beta_{2} L E G D P_{t}+r e s 2_{t} \\
& \operatorname{LSCO}_{t}=\beta_{0}+\beta_{1} L S E U_{t}+\beta_{2} L S G D P_{t}+r e s 3_{t} \\
& \operatorname{LTCO}_{t}=\beta_{0}+\beta_{1} L T E U_{t}+\beta_{2} L T G D P_{t}+\operatorname{res}_{t}
\end{aligned}
$$

Johansen eşbütünleşme testine göre, Meksika, Endonezya ve Türkiye verileri için Öz istatistiği ve Maximum Öz Değer İstatistiği sonuçlarının kritik değerden büyük olması sonucu boş hipotezin reddedilip alternatif hipotezin kabulünü gerekli kılmıştır. Seriler arasında yalnızca bir eşbütünleşme vektörü bulunduğu her iki istatistik tarafından da ortaya konulmaktadır. Meksika, Endonezya ve Türkiye'de ekonomik büyüme, enerji tüketimi ve karbon emisyonu arasında uzun dönemli bir ilişki mevcuttur. Ancak Güney Kore için Öz istatistiği ve Maximum Öz Değer İstatistiği sonuçlarının kritik değerden küçük olması sonucu boş hipotezin reddedilip alternatif hipotezin kabulünü gerekli kılmıştır. Güney Kore'de ekonomik büyüme, enerji tüketimi ve karbon emisyonu arasında uzun dönemli bir ilişkiye rastlanmamıştır.

Değişkenler arasındaki ilişkinin yönünü belirlemek amacıyla Granger nedensellik testi yapılmıştır. Granger nedensellik testi için önce seriler durağanlaştırılmış, yani birinci dereceden farkı alınmış, daha sonra Granger nedensellik testi uygulanmıştır.

Granger nedensellik testinde gecikme sayıları genellikle araştırmacılar tarafindan belirlenmekte olup test yapılırken gecikme uzunluğunun belirlenebilmesi için bir ön bilgi bulunmamaktadır. Literatürde gecikme değerleri, mevsimsel veriler kullanılarak yapılan çalışmalarda 4,8 veya 12 , aylık veriler kullanılarak yapılan çalışmalarda ise 12 ya da 24 olmak üzere çoğunlukla aynı büyüklükte ele alınmaktadır (Kadılar, 2000: 54).

\begin{tabular}{|c|c|c|c|c|c|}
\hline $\mathbf{H}_{0}$ Hipotezi & Ülke & F-istat. & Olasılık & Karar & Sonuç \\
\hline \multirow{4}{*}{ LCO2 Granger Nedeni Değildir LGDP } & Meksika & 3.577 & 0.013 & RET & 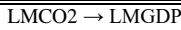 \\
\hline & Endonezya & 0.006 & 0.937 & KABUL & \\
\hline & Güney Kore & 0.796 & 0.372 & KABUL & \\
\hline & Türkiye & 0.446 & 0.508 & KABUL & \\
\hline \multirow{4}{*}{ LGDP Granger Nedeni Değildir LCO2 } & Meksika & 1.500 & 0.226 & KABUL & \\
\hline & Endonezya & 4.816 & 0.034 & RET & $\mathrm{LEGDP} \rightarrow \mathrm{LECO} 2$ \\
\hline & Güney Kore & 4.338 & 0.03 & RET & $\mathrm{LGGDP} \rightarrow \mathrm{LGCO} 2$ \\
\hline & Türkiye & 6.577 & 0.014 & RET & $\mathrm{LTGDP} \rightarrow \mathrm{LTCO} 2$ \\
\hline \multirow{4}{*}{ LEU Granger Nedeni Değildir LGDP } & Meksika & 1.816 & 0.144 & KABUL & \\
\hline & Endonezya & 4.219 & 0.994 & KABUL & \\
\hline & Güney Kore & 2.227 & 0.135 & KABUL & \\
\hline & Türkiye & 2.639 & 0.112 & KABUL & \\
\hline \multirow{4}{*}{ LGDP Granger Nedeni Değildir LEU } & Meksika & 2.945 & 0.030 & RET & $\mathrm{LMGDP} \rightarrow \mathrm{LMEU}$ \\
\hline & Endonezya & 4.897 & 0.033 & RET & LEGDP $\rightarrow$ LEEU \\
\hline & Güney Kore & 0.212 & 0.644 & KABUL & \\
\hline & Türkiye & 13.419 & 0.000 & RET & LTGDP $\rightarrow$ LTEU \\
\hline \multirow{4}{*}{ LEU Granger Nedeni Değildir LCO2 } & Meksika & 1.097 & 0.396 & KABUL & \\
\hline & Endonezya & 5.588 & 0.023 & RET & $\mathrm{LEEU} \rightarrow \mathrm{LECO} 2$ \\
\hline & Güney Kore & 0.500 & 0.479 & KABUL & \\
\hline & Türkiye & 0.409 & 0.526 & KABUL & \\
\hline \multirow{4}{*}{ LCO2 Granger Nedeni Değildir LEU } & Meksika & 0.911 & 0.505 & KABUL & \\
\hline & Endonezya & 0.165 & 0.686 & KABUL & \\
\hline & Güney Kore & 0.304 & 0.581 & KABUL & \\
\hline & Türkiye & 2.867 & 0.098 & KABUL & \\
\hline
\end{tabular}

Tablo: 8

\section{Granger Nedensellik Sonuçları}


Bu çalışmada nedensellik analizindeki gecikme uzunlukları, Akaike bilgi kriteri kullanılarak belirlenmiştir. Akaike bilgi kriteri kullanılarak yapılan nedensellik analizinin sonuçları ve hipotezleri Tablo 8'de gösterilmiştir.

Granger Nedensellik analizinin sonuçları, Meksika'da GDP ile $\mathrm{CO}_{2}$ arasında, $\mathrm{CO}_{2}$ 'den GDP'ye doğru tek yönlü bir nedensellik ilişkisi, EU ile GDP arasında, GDP'den EU'ye doğru tek yönlü bir nedensellik ilişkisinin olduğunu ortaya koymaktadır. Yani karbon emisyonundan büyümeye doğru ve büyümeden enerji tüketimine doğru tek yönlü bir nedensellik ilişkisi tespit edilmiştir. Bu tespite göre, incelenen dönemde $\% 5$ anlamlılık düzeyinde büyüme, enerji tüketimini ve karbon emisyonu ise büyümeyi etkilemektedir. $\mathrm{Bu}$ sonuç Hossain (2011)'in ekonomik büyümeden enerji tüketimine doğru nedensel bir ilişki vardır sonucuna ulaştığı çalışmayla aynı sonuçlar elde etmekte olup, bu çalışmada Hossain (2011)'in aksine değişkenler arasında kısa dönem değil, uzun dönem ilişkisi bulunduğu tespit edilmiştir.

Granger Nedensellik analizinin sonuçları, Endonezya'da GDP ile $\mathrm{CO}_{2}$ arasında, GDP'den $\mathrm{CO}_{2}$ 'ye doğru tek yönlü bir nedensellik ilişkisi, EU ile GDP arasında, GDP'den EU'ye doğru tek yönlü bir nedensellik ilişsisi ve EU ile $\mathrm{CO}_{2}$ arasında, EU'dan $\mathrm{CO}_{2}$ 'ye doğru tek yönlü bir nedensellik ilişkisi olduğunu ortaya koymaktadır. Yani büyümeden karbon emisyonuna ve enerji tüketimine doğru tek yönlü bir nedensellik ile enerji tüketiminden karbon emisyonuna doğru bir nedensellik ilişkisi tespit edilmiştir. Bu tespite göre, incelenen dönemde $\% 5$ anlamlılık düzeyinde büyüme, karbon emisyonu ve enerji tüketimini etkilemektedir. Bu sonuç Heidari ve diğ. (2014)'ün enerji tüketiminin karbon emisyonunu artırdığı bulgusuyla örtüşmektedir. Ancak Shahbaz ve diğ. (2013)'ün Endonezya için yapmış olduğu araştırmada ekonomik büyüme, enerji tüketimi, finansal ilerleme, uluslararası ticaret ve karbon emisyonu verilerini incelenip, ekonomik büyüme ve karbon emisyonu arasında iki yönlü bir nedensellik ilişkisi olduğunu ifade etmiştir. Bu çalışmada ise ekonomik büyümeden karbon emisyonuna doğru tek yönlü bir nedensellik bulunmasına karşın, ters yönlü bir nedenselliğe rastlanmamıştır.

Toda-Yamamoto nedensellik analizinin sonuçları, Güney Kore'de GDP ile $\mathrm{CO}_{2}$ arasında, GDP'den $\mathrm{CO}_{2}$ 'ye doğru tek yönlü bir nedensellik ilişkisinin olduğunu ortaya koymaktadır. Yani büyümeden karbon emisyonuna doğru tek yönlü bir nedensellik ilişkisi tespit edilmiştir. Bu tespite göre, incelenen dönemde $\% 5$ anlamlılık düzeyinde büyüme, karbon emisyonunu etkilemektedir.

Granger Nedensellik analizinin sonuçları, Türkiye'de GDP ile $\mathrm{CO}_{2}$ arasında, GDP'den $\mathrm{CO}_{2}$ 'ye doğru tek yönlü bir nedensellik ilişkisi, EU ile GDP arasında, GDP'den EU'ye doğru tek yönlü bir nedensellik ilişkisinin olduğunu ortaya koymaktadır. Yani büyümeden karbon emisyonu ve enerji tüketimine doğru tek yönlü bir nedensellik ilişkisi tespit edilmiştir. Bu tespite göre, incelenen dönemde $\% 5$ anlamlılık düzeyinde büyüme, karbon emisyonu ve enerji tüketimini etkilemektedir. Bu sonuç Yöntem (2011) ve Altıntaş (2013)'ın daha önceki çalışmalarındaki sonuçlara göre paralellik arz etmekte olup Halıcıoğlu (2009)'un enerji tüketimi, karbon emisyonu ve dış ticaret ile belirlenir sonucuna vardığ1 çalışmasındaki sonuç bu çalışmada elde edilememiştir. 
Türkiye'nin ekonomik açıdan büyümesiyle birlikte ortaya çıkan karbon emisyonu ve enerji tüketiminin de arttığg ve büyümenin bu artışa neden olduğu görülmektedir. Bununla birlikte ekonomik büyümenin enerji talebini artırdığı ve enerji kaynaklarının büyük bölümü fosil yakıt kaynaklı olduğundan karbon salınımını artırdığ 1 ve bu verilerin de uzun dönemde eş bütünleşik olduğu görülmektedir.

\section{Sonuç}

Bu çalışmada, yeni bir uluslararası oluşum olan MIST ülkelerinde, karbon emisyonu ve enerji tüketimi ile ekonomik büyüme arasında nedensellik ilişkisi 1971-2010 dönemi verileri kullanılarak test edilmiştir. Çalışma bulgularına göre Meksika'da karbon emisyonu arttığında ekonomik büyümenin arttığ1, ekonomik büyüme sonrasında enerji talebinin artması sonucu enerji tüketiminin de arttığı sonuçları elde edilmiştir. Endonezya için değerlendirildiğinde ekonomik büyümeden karbon emisyonuna doğru, ekonomik büyümeden enerji tüketimine doğru ve enerji tüketiminden karbon emisyonuna doğru tek yönlü bir nedensellik ilişkisi olduğu bulgusuna ulaşılmıştır. Sonuçlar Güney Kore için değerlendirildiğinde ekonomik büyümeden karbon emisyonunu doğru tek yönlü bir nedensellik ilişkisi olduğu sonucu elde edilmiştir. Türkiye için değerlendirildiğinde ise ekonomik büyümeden karbon emisyonuna doğru ve ekonomik büyümeden enerji tüketimine doğru tek yönlü bir nedensellik ilişkisi olduğu sonucu elde edilmiştir.

Kısaca MIST ülkeleri verileri kullanılarak yapılan bu çalışmada, söz konusu ülkelerde ekonomik büyümeden karbon emisyonu ve enerji tüketimine doğru tek yönlü bir nedensellik olduğu ile ilgili genel bir eğilim ortaya çıkmaktadır. Ters yönlü, yani karbon emisyonu ve enerji tüketiminden ekonomik büyümeye doğru bir nedensellik eğilimi ortaya çıkmamıştır. Diğer bir deyişle ekonomik büyümedeki değişimler karbon emisyonu ve enerji tüketimindeki değişimlerden önce gelmektedir. Ekonomik büyümenin artışı, karbon emisyonunu ve enerji talebini artırmakta ya da ekonomik daralma sonucunda karbon emisyonunda düşüş ve enerji arzında fazla oluşmasına sebep olmaktadır. Yani MIST ülkelerinde ekonomik büyümenin bir göstergesi olan GSYH'deki değişmelerin sonrasında karbon emisyonu ve enerji tüketiminde değişmeler olmaktadır. Dolayısıyla MIST ülkelerinin büyümeleri enerji ve karbon emisyon faktörüne daha az bağımlı olduğundan enerji tasarrufu sağlayan ve karbon emisyonunu azaltan enerji politikalarının daha etkin olacağı söylenebilir. Bu sonuçlar enerji politikalarının çevreye daha az karbon salınımı yaratan temiz enerji alanlarına yönelmesi gerektiğine 1 şı tutmaktadır.

Diğer yandan etkin enerji kullanımına yönelik stratejiler geliştirmek, elektrik üretiminde fosil yakıtlara bağlı kalmadan yenilenebilir enerji kaynakları kullanılarak üretim yapılmasını teşvik edici politikaları hayata geçirmek sürdürülebilir kalkınma ve enerji güvenliği açısından kritik öneme sahip olduğu belirgin hale gelmektedir.

\section{Kaynaklar}

Abid, M. (2015), “The Close Relationship Between Informal Economic Growth and Carbon Emissions in Tunisia Since 1980 : The (ir)Relevance of Structural Breaks", Sustainable Cities and Society, 15, 11-21. 
Acaravc1, A. \& I. Öztürk (2010), “On the Relationship between Energy Consumption, $\mathrm{CO}_{2}$ Emissions and Economic Growth in Europe", Energy, 35(12), 5412-5420.

Alam, M.J. \& I.A. Begum \& J. Buysse \& S. Rahman \& G. Van Huylenbroeck (2011), "Dynamic Modeling of Causal Relationship Between Energy Consumption, $\mathrm{CO}_{2}$ Emissions and Economic Growth in India", Renewable and Sustainable Energy Reviews, 15(6), 32433251 .

Alkhathlan, K. \& M. Javid (2013), "Energy Consumption, Carbon Emissions and Economic Growth in Saudi Arabia: An aggregate and disaggregate analysis", Energy Policy, 62, 1525-1532.

Al-Mulali, U. \& C.N. Binti Che Sab (2012), "The Impact of Energy Consumption and $\mathrm{CO}_{2}$ Emission on the Economic Growth and Financial Development in the Sub Saharan African Countries", Energy, 39(1), 180-186.

Alshehry, A.S. \& M. Belloumi (2015), "Energy Consumption, Carbon Dioxide Emissions and Economic Growth: The Case of Saudi Arabia”, Renewable and Sustainable Energy Reviews, 41, 237-247.

Altintaş, H. (2013), “Türkiye'de Birincil Enerji Tüketimi, Karbondioksit Emisyonu ve Ekonomik Büyüme İlişkisi: Eş - Bütünleşme ve Nedensellik Analizi”, Eskişehir Osmangazi Üniversitesi İktisadi ve İdari Bilimler Fakültesi Dergisi, (8), 263-294.

Arouri, M.E.H. \& A. Ben Youssef \& H. M'henni \& C. Rault (2012), "Energy Consumption, Economic Growth and $\mathrm{CO}_{2}$ Emissions in Middle East and North African Countries", Energy Policy, 45, 342-349.

Aytun, C. (2014), “Gelişen Ekonomilerde Karbondioksit Emisyonu, Ekonomik Büyüme ve Eğitim Arasındaki İlişki: Panel Veri Analizi”, International Journal of Social Science, 27, 339352.

Bastola, U. \& P. Sapkota (2014), "Relationships among Energy Consumption, Pollution Emission, and Economic Growth in Nepal", Energy, 1-9.

Bloch, H. \& S. Rafiq \& R. Salim (2012), "Coal Consumption, $\mathrm{CO}_{2}$ Emission and Economic Growth in China: Empirical Evidence and Policy Responses", Energy Economics, 34(2), 518528.

Cowan, W.N. \& T. Chang \& R. Inglesi-Lotz \& R. Gupta (2014), “The Nexus of Electricity Consumption, Economic Growth and $\mathrm{CO}_{2}$ Emissions in the BRICS Countries", Energy Policy, 66, 359-368.

Çevre ve Orman Bakanlığı (2011), Karbon Piyasalarında Ulusal Deneyim ve Geleceğe Bakış, Ankara.

Dursun, G. (2015), “Türkiye’de Reel Döviz Kuru Belirsizliği ve Yurtiçi Yatırımlar”, Eskişehir Osmangazi Üniversitesi İ̈BF Dergisi, 10(1), 99-118.

Dünya Bankas1, World Development Indicators, <http://databank.worldbank.org>, 28.12.2014.

Elbasan, P. (2011), Yeni Bir Uluslararası Oluşum: MIST, Bilgesam, Bilge Adamlar Stratejik Araştırmalar Merkezi, 18 Kasım 2011.

Fei, L. \& S. Dong \& L. Xue \& Q. Liang \& W. Yang (2011), "Energy Consumption-Economic Growth Relationship and Carbon Dioxide Emissions in China”, Energy Policy, 39(2), 568-574.

Geller, H. (2002), Energy Revolution: Policies for a Sustainable Future, Island Pres, Washington DC. 
Granger, C.W.J. (1988), “Causality, cointegration, and control”, Journal of Economic Dynamics and Control, 12(2), 551-559.

Halıcıoğlu, F. (2009), “An Econometric Study of CO2 Emissions, Energy Consumption, Income and Foreign Trade in Turkey”, Energy Policy, 37(3), 1156-1164.

Heidari, H. \& S.T. Katircioğlu \& L. Saeidpour (2015), "Economic Growth, $\mathrm{CO}_{2}$ Emissions, and Energy Consumption in the Five ASEAN Countries", International Journal of Electrical Power\&Energy Systems, 64, 785-791.

Hossain, S. (2011), "Panel Estimation for $\mathrm{CO}_{2}$ Emissions, Energy Consumption, Economic Growth, Trade Openness and Urbanization of Newly Industrialized Countries", EnergyPolicy, 39(11), 6991-6999.

Jahangir A.M. \& I.A. Begum \& J. Buysse \& G. van Huylenbroeck (2012), "Energy Consumption, Carbon Emissions and Economic Growth Nexus in Bangladesh: Cointegration and Dynamic Causality Analysis", Energy Policy, 45, 217-225.

Johansen, S. \& K. Juselius (1990), "Maximum Likelihood Estimation and Inference on Cointegration-with Applications to the Demand for Money", Oxford Bulletin of Economics and Statistics, 52(2), 169-210.

Kadılar, C. (2000), Uygulamalı Çok Değişkenli Zaman Serileri Analizi, Büro Basımevi, Ankara.

Karakaya, E. \& M. Özcağ (2003), “Turkiye Açısından Kyoto Protokolü’nün Değerlendirilmesi ve Ayrıştırma (Decomposition) Yöntemi ile $\mathrm{CO}_{2}$ Emisyonu Belirleyicilerinin Analizi”, VII. ODTU Ekonomi Konferansi, 6-9 Eylul 2003.

Kasman, A. \& Y.S. Duman (2015), “ $\mathrm{CO}_{2}$ Emissions, Economic Growth, Energy Consumption, Trade and Urbanization in New EU Member and Candidate Countries: A Panel Data Analysis", Economic Modelling, 44, 97-103.

Kofi, A.P. \& W. Bekoe \& F. Amuakwa-Mensah \& J.T. Mensah \& E. Botchway (2012), "Carbon Dioxide Emissions, Economic Growth, Industrial Structure, and Technical Efficiency: Empirical Evidence from Ghana, Senegal, and Morocco on the Causal Dynamics", Energy, 47(1), 314-325.

Liao, H. \& H.S. Cao (2013), "How Does Carbon Dioxide Emission Change With The Economic Development? Statistical Experiences from 132 Countries", Global Environmental Change, 23(5), 1073-1082.

Loganathan, N. \& M. Shahbaz \& R. Taha (2014), "The Link between Green Taxation and Economic Growth on $\mathrm{CO}_{2}$ Emissions: Fresh Evidence from Malaysia", Renewable and Sustainable Energy Reviews, 38, 1083-1091.

Lotfalipour, M.R. \& M.A. Falahi \& M. Ashena (2010), "Economic Growth, $\mathrm{CO}_{2}$ Emissions, and Fossil Fuels Consumption in Iran”, Energy, 35(12), 5115-5120.

Menyah, K. \& Y. Wolde-Rufael (2010), "Energy Consumption, Pollutant Emissions and Economic Growth in South Africa", Energy Economics, 32(6), 1374-1382.

Munasinghe, M. (2001), “Towards Sustainomics”, The Sustainability of Long Term Growth, Eds.Mohan Munasinghe, Osvaldo Sunkel, Carlos de Miguel, Cheltenham, UK; Northampton, MA, USA, 43-44.

Omrı, A. (2013), " $\mathrm{CO}_{2}$ Emissions, Energy Consumption and Economic Growth Nexus in MENA Countries: Evidence from Simultaneous Equations Models”, Energy Economics, 40, 657664. 
Özcan, B. (2013), “The Nexus between Carbon Emissions, Energy Consumption and Economic Growth in Middle East Countries: A Panel Data Analysis", Energy Policy, 62, 11381147.

Öztürk, I. \& A. Acaravc1 (2013), "The Long-Run and Causal Analysis of Energy, Growth, Openness and Financial Development on Carbon Emissions in Turkey", Energy Economics, 36, 262-267.

Pao, H.T. \& Y.Y. Li (2014), "Clean Energy, Non-Clean Energy, and Economic Growth in the MIST Countries”, Energy Policy, 67, 932-942.

Pao, H.T. \& C.M. Tsai (2011), "Multivariate Granger Causality between $\mathrm{CO}_{2}$ Emissions, Energy Consumption, FDI (foreign direct investment) and GDP (gross domestic product): Evidence from a Panel of BRIC (Brazil, Russian Federation, India, and China) Countries", Energy, 36(1), 685-693.

Park, J. \& T. Hong (2013), “Analysis of South Korea's Economic Growth, Carbon Dioxide Emission, and Energy Consumption Using The Markov Switching Model”, Renewable and Sustainable Energy Reviews, 18, 543-551.

Saboori, B. \& M. Sapri \& M. Bin Baba (2014), "Economic Growth, Energy Consumption and $\mathrm{CO}_{2}$ Emissions in OECD (Organization for Economic Co-operation and Development)'s Transport Sector: A Fully Modified Bi-Directional Relationship Approach”, Energy, 66, 150-161.

Salahuddin, M. \& J. Gow (2014), "Economic Growth, Energy Consumption and $\mathrm{CO}_{2}$ Emissions in Gulf Cooperation Council Countries", Energy, 73, 44-58.

Sarısoy, S. \& F. Yıldız (2013), "Karbondioksit $\left(\mathrm{CO}_{2}\right)$ Emisyonu ve Ekonomik Büyüme İlişkisi: Gelişmiş ve Gelişmekte Olan Ülkeler İçin Panel Veri Analizi”, Sosyal Bilimler Metinleri, 2, 1-28.

Sbia, R. \& M. Shahbaz \& H. Hamdi (2014), "A Contribution of Foreign Direct Investment, Clean Energy, Trade Openness, Carbon Emissions and Economic Growth to Energy Demand in UAE", Economic Modelling, 36, 191-197.

Shahbaz, M. \& Q.M.A. Hye \& A.K. Tiwari \& N.C. Leitão (2013), "Economic Growth, Energy Consumption, Financial Development, International Trade and $\mathrm{CO}_{2}$ Emissions in Indonesia”, Renewable and Sustainable Energy Reviews, 25, 109-121.

Soytas, U. \& R. Sari \& B.T. Ewing (2007), "Energy Consumption, Income, and Carbon Emissions in The United States", Ecological Economics, 62(3-4), 482-489.

Tutulmaz, O. \& A. Şahinöz \& S. Çağatay (2012), "Karbondioksit Emisyonu Üzerinden Çevre Baskısı Değerlendirmesi: Çevresel Kuznets Eğrisine Panel Veri Uygulaması", Iktisat İşletme ve Finans, 27(314), 35-72.

Van Hoa, T. \& K. Limskul (2013), "Economic Impact of $\mathrm{CO}_{2}$ Emissions on Thailand's Growth and Climate Change Mitigation Policy: A Modelling Analysis”, Economic Modelling, 33, 651-658.

Yöntem, G. (2013), “Ekonomik Büyüme Ve Karbon Salınımı Arasındaki İlişkinin Nedensellik Analizi: Türkiye Örneği”, Yıldız Teknik Üniversitesi İ.I.B.F. Dergisi, 1-11.

Zhang, X.P. \& X.M. Cheng (2009), "Energy Consumption, Carbon Emissions, and Economic Growth in China”, Ecological Economics, 68(10), 2706-2712.

Zivot, E. \& D.W.K. Andrews (1992), "Further Evidence on the Great Crash, the Oil-Price Shock, and the Unit-Root Hypothesis", Journal of Business \& Economic Statistics, 10(3), 251270. 


\section{EKLER}

EK: 1

MCO2 Meksika'nın kiși bașına düșen karbondioksit emisyonu

MEU Meksika'nın kişi başına düşen enerji tüketimi

ECO2 Endonezya'nın kiși bașına düșen karbondioksit emisyonu

EEU Endonezya'nın kişi başına düşen enerji tüketimi

MGDP Meksika'nın reel Gayrisafi yurt içi hasıla (Sabit, 2005 yılı, ABD

Doları)

GCO2 Güney Kore'nin kişi başına düşen karbondioksit emisyonu

GEU Güney Kore'nin kişi başına düşen enerji tüketimi

EGDP

Endonezya'nın reel Gayrisafi yurt içi hasıla (Sabit, 2005 yılı,

ABD Dolar1)

GGDP Güney Kore'nin reel Gayrisafi yurt içi hasıla (Sabit, 2005 yılı, ABD Dolar1)

TCO2 Türkiye'nin kişi başına düşen karbondioksit emisyonu

TEU Türkiye'nin kişi başına düșen enerji tüketimi

TGDP Türkiye'nin reel Gayrisafi yurt içi hasıla (Sabit, 2005 yılı, ABD

EK 2 Dolar1)

Meksika

$\operatorname{MCO2}$

MEU

MGDP

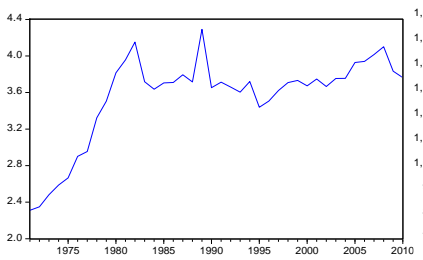

$\mathrm{ECO2}$

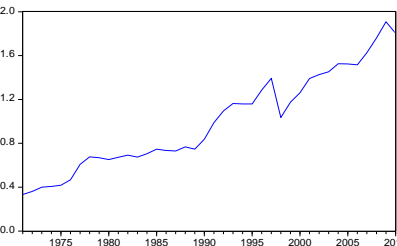

GCO2

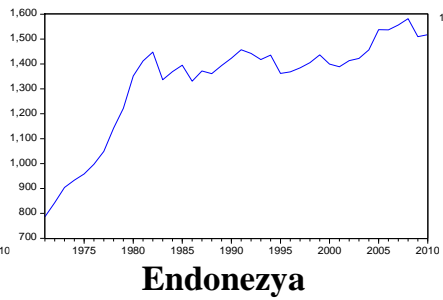

EEU

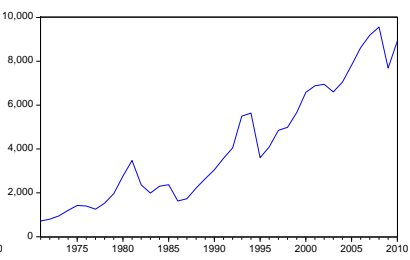

EGDP

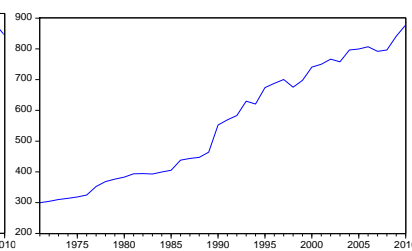

Güney Kore

GEU

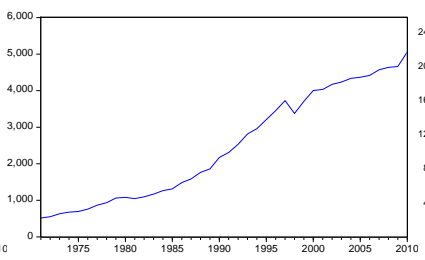

Türkiye

TEU

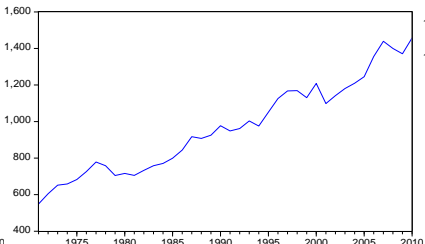

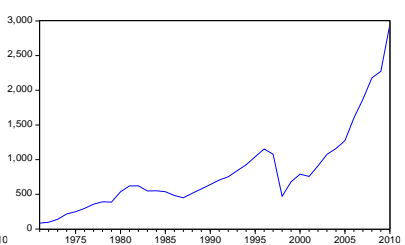

GGDP

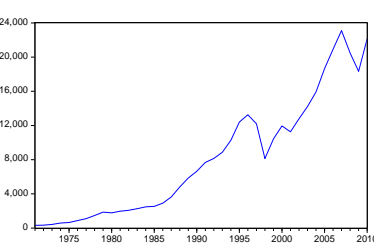

TGDP

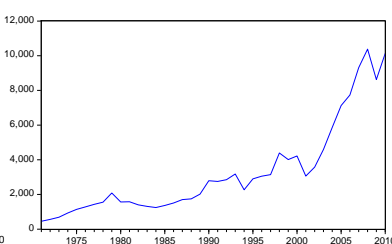

